\title{
Territorios de la negridad en Colombia: de las expoliaciones, extrahecciones a las re- existencias en el valle del Patía'
}

\author{
Territories of blackness in Colombia: spoliation, \\ extraheccion and re-existences in the Patía Valley
}

Yilver Mosquera-Vallejo² (1)

\begin{abstract}
RESUMEN
En este artículo analizamos los procesos de expoliación y extrahección en el valle del Patía desde 1960 hasta el 2017, asimismo reflexionamos acerca del modo en que se destilan en el espacio las re-existencias. Igualmente, argumentamos que los procesos de expoliación a la gente negra fueron agenciados por dinámicas de acumulación de la tenencia de la tierra, y estudiamos a las extrahecciones que fueron resultado de la minería ilegal. Por último, conceptualizamos a las re-existencias, movilizadas mediante matrices de subjetividad y territorialidad otras. Esto fue complementado con entrevistas, mapas y censos de tenencia de la tierra. Finalmente, establecemos que estos procesos configuran formas de apropiar el valle del Patía mediadas a través de relaciones de poder y modos de conocer y hacer territorio.
\end{abstract}

Palabras claves: valle del Patía, expoliación, extrahección, re-existencias.

\section{ABSTRACT}

This article analyzes the processes of looting and extrahección in the Patía Valley from 1960 to 2017. It reflexes on the ways in which re-existences are distilled in space. Likewise, I argue that the processes of robbery of black people were caused by dynamics of accumulation of land tenure, linked to the extrahecciones that were the result of illegal mining. In addition, the text conceptualizes the re-existences mobilized through matrices of subjectivity and other territorialities. Interviews, maps, and land tenure censuses complement this study. Finally, I argue that these processes configure ways of appropriating the Patía valley through power relations and ways of knowing and making territory.

Key words: expoliation, extraheccion, re-existences, Patía Valley.

Esta investigación fue posible gracias al apoyo del Estado chileno, a través de una beca de doctorado nacional, en el año 2016, Agencia Nacional de Investigación y Desarrollo de Chile. Se inscribe, además, en el marco del proyecto en ejecución de tesis doctoral titulado Geografías de la negridad: prácticas del 'adentro' y 'afuera' en la construcción del territorio en el valle del Patía, 1960-2017 (Colombia). Mis agradecimientos a María Fernanda Anaya Chamorro por su ayuda en la elaboración de la cartografía temática, y sus comentarios a una versión previa de este texto. No obstante, los desaciertos son de mi exclusiva responsabilidad.

Doctor (c ) en Geografía por la Pontificia Universidad Católica de Chile (Chile). Correo electrónico: yamosquera@uc.cl ORCID: https://orcid. org/0000-0001-9262-9081 
Reflexionar acerca de la expoliación, extrahección y sus relaciones con las formas en que se re- existe en el territorio, o dicho de otra manera cómo este es producido, representa el propósito en estas líneas. Despojar, desplazar, someter y menoscabar constituyen los significantes, a partir de los cuales es posible explicar la expoliación y la extrahección en un espacio determinado. Según la autoridad del diccionario de la Real Academia Española (RAE), expoliar tiene un solo significado: es la apropiación de algo que pertenece a otra persona de forma violenta o injusta. Extrahección, proviene del latín "extrahere" que significa tomar algo quitándolo. Ahora bien, dicho esquemáticamente, extrahección, se presenta aquí "para referirse al acto de tomar o quitar con violencia o donde se "arrancan" los recursos naturales, sea de las comunidades como de la Naturaleza" (Gudynas, 2013:11).

El propósito de este artículo fue doble: por una parte, analizar los procesos y dinámicas de expoliación, y extrahección en el valle del Patía desde 1960 hasta el 2017, y por otra parte, reflexionar el modo en que se destilan e inscriben en el espacio las re-existencias o formas de re-inventar la vida cotidiana a la luz de los procesos señalados. En este sentido, el manuscrito se abordó desde tres ángulos complementarios. Primero, argumentamos que los procesos de expoliación a la gente negra del valle del Patía se han presentado a partir de desterritorializaciones, agenciadas por dinámicas de acumulación de la estructura de tenencia de la tierra por parte de colonos blan$\cos /$ mestizos, situación que se consolida desde la década de los años sesenta. Segundo, estudiamos a las extrahecciones en el valle del Patía, pues esta se basa en la extracción de los recursos naturales, a partir de la violación de los derechos humanos y de la naturaleza. En este contexto, identificamos a la minería ilegal mecanizada en El Hoyo-Patía y en el río Sambingo como ejemplos de extrahecciones ocurridas en el ámbito de estudio. En tercera instancia, abordamos las re-existencias en tanto más que resistencias agenciadas por matrices de racionalidad (Porto-Goncalves, 2006), subjetividad y territorialidad otras que re-construyen una serie de prácticas localizadas y distribuidas, esto es, espacializadas en el "adentro".

Las preguntas orientadoras de este trabajo son: ¿ qué procesos y dinámicas de expoliación a la gente negra se han presentado en el valle del Patía desde la década iniciada en 1960 hasta el 2014? ¿cuáles fueron las implicaciones socioambientales de la extrahección minera ilegal en el valle del Patía entre 2013 y 2017? Y, por último, nos cuestionamos ¿a través de qué tipo de prácticas los patianos re-existen frente a los procesos de expoliación y extrahección? La estrategia metodológica consistió en la interpretación y análisis contextual de diferentes conceptos (extrahección, expolio, re-existencia), revisando fuentes secundarias, que incorporaron instrumentos metodológicos, como: datos de la estructura agraria en 1994 (Trujillo, 1996), estadísticas distribución predial IGAC (2014), entrevistas semiestructuradas y representación espacial a través de mapas. Con respecto al uso de las categorías de análisis, no se buscó ofrecer definiciones finalizadas de estos, sino más bien se operó con diferentes conceptualizaciones que están fuertemente interrelacionadas entre ellas.

El manuscrito está organizado de la siguiente manera. Primero, se consideró una perspectiva territorial y analítica, que a su vez está subdividida en diferentes énfasis, a saber: a) los estudios hacia la gente negra en Colombia, que constituyen los antecedentes con el fin de hacer notar algunos de los temas y enfoques conceptuales abordados desde los estudios afrocolombianos. Enseguida, b) identificamos las trayectorias históricas y espaciales de los patianos, y marcamos el proceso genealógico definido en esta investigación desde la década de 1960, debido a que en esta época se consolidaron dinámicas de desterritorialización material de los patianos por parte 
de los colonos. Una vez definida la perspectiva territorial, c) hemos desarrollado las aproximaciones analíticas, y elaborado una pieza conceptual con base en las categorías de expoliación, extrahección y re-existencias, a las que analizamos a la luz de los procesos y relaciones territoriales posibles de indagar a partir de ellas.

En segunda instancia, se han interpretado los procesos señalados en el valle del Patía desde la idea de expolio de la tierra a la gente negra, pero en tanto proceso de desterritorialización; la minería ilegal a partir del concepto de extrahección y las re-existencias como modalidades que son más que resistencias, debido a que implican existir en subjetividades, territorialidades, racionalidades otras, y en su agenciamiento adquieren diferente significatividad territorial. De forma complementaria, usamos un mapa que identifica las extrahecciones en el río Sambingo, así como dos gráficas que nos muestran para el año 1994 y 2014 las concentraciones en la tenencia de la tierra. Para leer las re-existencias desde una mirada territorial nos basamos en la idea de prácticas del "adentro". Por último, tenemos las consideraciones finales del artículo que concluyen el trabajo.

\section{Contexto territorial y encuadre analítico}

Este valle interandino se encuentra ubicado al suroccidente de Colombia, entre los departamentos de Cauca y Nariño. Es un espacio que divide en dos a la cordillera de los Andes, su drenaje principal es el río Patía, el cual forma planicies fértiles en las que se presentan diferentes actividades económico-productivas. Asimismo, esta zona presenta alta biodiversidad y sus ecosistemas son de bosque seco tropical Bs-t, los cuales han sido transformados con mayor intensidad en los últimos cincuenta años, debido a la actividad antrópica.

Figura № 1. Localización del área de estudio

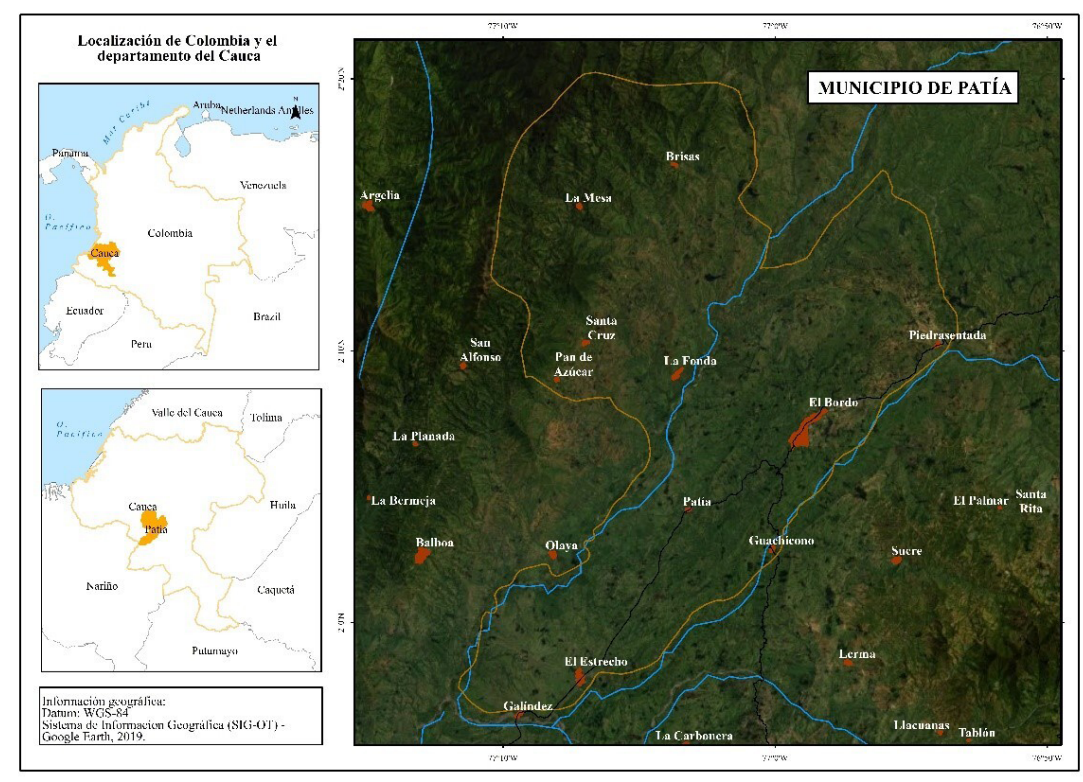

Fuente: elaboración propia con base en Google Earth, 2019. 
Las investigaciones sobre poblaciones negras en Colombia han sido abordadas desde diferentes enfoques teóricos -contemporáneos o clásicos-, desde los cuales se ha indagado acerca de distintas problemáticas. Velandia y Restrepo (2017), establecen una periodización de los estudios afrocolombianos en dos grandes líneas. La primera, a partir de enfoques teóricos clásicos, que ellos distinguen en su genealogía como: a) pioneros, desde los años cincuenta a mediados de los sesentas; b) emergencia, inicia en la segunda mitad de los sesentas y termina en los ochentas; c) consolidación, la cual comienza desde la segunda mitad de los ochentas hasta finales de los noventas (Velandia \& Restrepo, 2017). La segunda línea que establecen en su genealogía es en los enfoques teóricos contemporáneos, y su fase correspondiente es la eclosión de los estudios afrocolombianos, la cual inicia desde la década de los años 2000 hasta la actualidad (2020). Algunas investigaciones en este campo transitan teóricamente por paradigmas como opción decolonial (Albán, 2015), posestructuralismo (Escobar, 1999), giro territorial y espacial (Offen, 2009; Mosquera-Vallejo 2020), entre otros. Estas perspectivas a su vez han dado lugar a diferentes problemáticas como dinámicas raciales, espacio y movimientos sociales (Oslender, 2002), giro al multiculturalismo (Wade, 2004), etnización (Restrepo, 2013), extractivismo minero (Restrepo 2017; Mosquera-Vallejo \& Paulsen-Espinoza, 2020), entre otros. Este trabajo lo situamos dentro del campo de los estudios afrocolombianos, es decir, estudiamos un territorio de gente negra desde una serie de problemáticas, categorías, improntas y trayectorias espaciales e históricas. En este sentido, nuestro objetivo consistió en analizar los procesos y dinámicas de expoliación, extrahección y las re-existencias en el valle del Patía desde 1960 hasta el 2017.

\section{Aproximaciones analíticas}

La propuesta conceptual de este trabajo consta de tres puntos principales:

Expoliación: el expolio es una palabra que encapsula diferentes conceptualizaciones. De acuerdo con la autoridad del diccionario de la Real Academia Española (RAE), expoliar se puede entender como "despojar algo o a alguien con violencia o con iniquidad" (RAE, s.f). El expolio puede ser comprendido como aquel "botín del vencedor" (RAE, s.f). La conceptualización académica del expolio se moviliza entre el arte, especialmente a través de la iconografía cristiana, arqueología, patrimonio y derecho. En el campo de la geografía, las concepciones de expolio no se distancian de las citadas. Desde algunas perspectivas de análisis en geografía humana, la expoliación es un concepto "temido (...) dado que cuenta con un potencial que trasciende lo meramente académico y alcanza lo político" (Hidalgo et al., 2016: 43). El expolio sugiere ausencia o precariedad en el acceso a la tierra (Kowarick, 1996), y a su vez, el proceso expoliativo podría entenderse como una modalidad de despojo que, en el contexto de expansión intrínseco del capitalismo, genera en los desposeídos la sensación o idea que algo está faltando. Por lo tanto: "si expoliar es negar el acceso a la posesión de algo, la alternativa es la apropiación de aquello por parte de los desposeídos" (Hidalgo et al., 2016: 43). Igualmente, "la expoliación sólo puede ser entendida como producto histórico" (Kowarick, 1996: 737) y en tanto producto histórico-geográfico, es necesario reconocer que el proceso expoliativo opera de maneras distintas. Esto es, el proceso de producción de la expoliación se adapta a las condiciones del lugar de forma diferenciada. Por consiguiente, las improntas, los mecanismos y las dinámicas del expolio en las áreas metropolitanas, se desplaza en niveles distintos a como es movilizado en las áreas rurales. El valle del Patía es un espacio rural, por lo tanto, nuestra forma de comprender esta categoría se encuentra construida, a partir de la especificidad del lugar. 
En este contexto, entendemos expoliación con procesos de apropiaciones de algo, a través de formas violentas o injustas que implican heterogeneidades en las formas de hacer y decir, esto es en las prácticas, que van desde procesos materiales/simbólicos de desterritorialización (Haesbaert, 2011) hasta dinámicas de apropiación cultural de prácticas estéticas, gastronómicas, musicales por parte de un grupo dominante a otro subalterno. De igual manera, los procesos que producen las expoliaciones configuran formas más o menos violentas en las que se registran y construyen una serie de relaciones espaciales que a través de distintos discursos, prácticas y relaciones de poder elaboran una serie de rugosidades que se inscriben, sedimentan y erosionan en el espacio geográfico. Es decir, son simultáneamente fijas y móviles. La expoliación siempre es un fenómeno violento, no importan las nuevas o viejas fórmulas que se usen para el proceso expoliativo, jamás pasa inadvertida, segrega a los desposeídos por un lado a partir de instrumentos jurídicos, y al mismo tiempo con el despliegue de los fusiles se corren los alambres. Podemos pensar aquí, por ejemplo, en el despojo de la tierra a la gente negra en el norte del Cauca por parte de los industriales de la caña de azúcar (Mina, 1975) o en los paisajes del despojo en los Montes de María (Ojeda et.al, 2015) como particulares formas de expoliación.

Extrahección: Recientemente se ha acuñado este término para hacer referencia a la apropiación de recursos naturales impuesta con violencia y quebrando el marco de derechos humanos y de la naturaleza (Gudynas, 2013). De tal suerte que, la extrahección viene a configurarse como una brutal forma de esquilmación. Esto es, un conjunto de métodos para menoscabar, empobrecer o agotar una fuente de riqueza por su extracción en exceso. En este contexto, esquilmar vendría a ser una modalidad más cruda y puntual de expoliación, en tanto que implica procesos de socio-ecológicos de apropiación excesivamente violentos y en menor tiempo. Más aún, y ahondando en nuestra perspectiva de la extrahección, es dable sostener que ella es una combinación de las formas en que el esquilmo y el expolio se inscriben simbólicamente en el espacio y materialmente en el paisaje. Sin embargo, una particularidad que resulta importante en relación con la extrahección es que va más allá del extractivismo en tanto que no se reduce a la simple extracción de un recurso natural, sino que esta incorpora la violencia y la violación de los derechos humanos y de la naturaleza como procesos inmanentes para llevar a cabo la apropiación del recurso. En palabras de Gudynas:

la extracción de recursos naturales no sólo desencadena impactos sociales y ambientales, sino que para que sea posible se apela a la violencia y se violan los derechos, tanto humanos como de la Naturaleza. Existen muchos ejemplos donde la extracción acarreó esas violaciones, tales como la afectación de la salud humana por contaminación, el desplazamiento forzado de comunidades, y otras, hasta llegar al asesinato de líderes ciudadanos. Por lo tanto, parece necesario contar con un término que identifique estas situaciones donde la extracción de los recursos naturales cruza límites sustantivos para violar los derechos. (Gudynas, 2013: 11).

La extrahección es una importante categoría para pensar dinámicas y procesos que configuran prácticas socioespaciales que se destilan violentamente en el espacio e implican disrupciones que se manifiestan en el acceso, uso y control sobre los recursos naturales, violaciones a marcos regulatorios de los derechos humanos de cada país, normas constitucionales de protección del medio ambiente y tratados internacionales de protección de pueblos tribales. Desde esta perspectiva, los procesos de extrahección se producen en el marco de una interseccionalidad, en 
tanto que, en ellos se enredan diferentes actores inscritos en distintas categorías sociales con prácticas que se sedimentan en el espacio de forma diferenciada. De esta forma, podemos pensar aquí como ejemplos de ello, a algunos extractivismos como el del caucho a finales del siglo XIX y principios del XX (Palacios, 2006), el extractivismo forestal en el Pacífico colombiano (Leal \& Restrepo, 2003) y más recientemente, la extracción ilegal mecanizada de oro en las comunidades negras del norte del Cauca (Restrepo, 2017) o la minería ilegal en El Hoyo-Patía (Melo-Guzmán, 2018).

Re-existencias: Este término tiene su origen en la geografía latinoamericana, concretamente a partir del trabajo de Porto-Gonçalves, (2001) y se ha convertido en una categoría atractiva para cuestionarse ciertas relaciones, matrices, prácticas instauradas en el mundo moderno/colonial. La re-existencia, es un sentido radical de la resistencia (Maldonado-Torres, 2017), de nuevos "sujetos que reivindican un lugar en el mundo" (Porto-Gonçalves, 2001: 220). Re-existir, es una actitud que implica no solo modos de conocer, ser y estar en el mismo, sino también, "incorpora crear maneras de existir, lo que incluye formas de sentir, de pensar, y de actuar en un mundo que se va construyendo el mismo a través de variadas insurgencias e irrupciones que buscan constituirlo como un mundo humano (Maldonado-Torres, 2017: 26). La re-existencia, sugiere la elaboración de subjetividades, territorialidades y prácticas socioculturales otras, sostenidas, agenciadas y movilizadas por epistemologías y ontologías otras en relación con las propuestas por el mundo moderno/colonial. Esta re-invención de la diferencia (Porto-Gonçalves, 2001), lleva a la ampliación de las formas de conocer, ser y estar en el mundo (Grosfoguel, 2016). Se trata ya no de una única manera de conocer, existir y resistir en una universalidad, sino de múltiples posibilidades que se abren en una suerte de pluriversalidades.

Nuestra apuesta por las re-existencias, en tanto sentido de supervivencia y de la vida (Leff, 2009), toman énfasis en los procesos de construcción de modalidades de dar sentido al mundo por sujetos ubicados en las zonas del no ser (Grosfoguel, 2012). Esto hace que re-existir se convierta en un concepto que trasciende lo académico, político, y deviene en un principio básico que permite la sostenibilidad espacio/temporal de subjetividades, territorialidades y prácticas socioculturales otras en diferentes ámbitos del mundo, y concretamente del sur global. En este contexto, las re-existencias adquieren múltiples sentidos empíricos y se hace necesario geografizar los procesos y prácticas que la movilizan, es decir, situarlos dentro de un contexto territorial y en el marco de unas relaciones espaciales para comprender cómo en determinados lugares operan unas re-existencias con unos significados particulares. En este sentido, es necesario reconocer que si las re-existencias se inscriben en unas singulares formas de vida, que abarcan desde prácticas gastronómicas hasta el papel que le es asignado a la música local, la tradición oral, los conocimientos locales en tanto actos simbólicos y políticos, su geograficidad surge como un punto de apoyo principal para darle sentido a la elaboración de subjetividades, territorialidades y racionalidades otras que han logrado reinventarse y reivindicar su lugar en el mundo (Porto-Gonçalves, 2001).

De esta forma, las re-existencias vistas desde un punto de vista geográfico, se constituyen en lugares que ontológica y epistemológicamente articulan prácticas lugarizadas que devienen en una serie de formas de percibir e imaginar el espacio y al mismo tiempo tejen entramados espaciales en los que se co-construyen dinámicas materiales/simbólicas que responden a lógicas ajenas a lo hegemónico. En esta dirección podríamos situar el trabajo del artista Adolfo Albán sobre las comunidades negras del valle del Patía, en el cual muestra como la práctica gastronó- 
mica adquiere unos sentidos políticos y simbólicos, que configuraron la comida como un acto de resistencia y re-existencia (Albán, 2015).

\section{El valle del Patía: un territorio expoliado}

Durante la tercera década del siglo $\mathrm{XX}$, cambios importantes empezaron a denotarse en la configuración socioespacial del valle del Patía, cuando colonos procedentes de otras regiones del país, conscientes del potencial ganadero y agrícola, así como del excedente que podrían sacar de esta región, fueron comprando y delimitando con alambres de púas los terrenos a los que se habian hecho. Este proceso tuvo las siguientes características de acuerdo con la tradición oral. En primera instancia, aquellos nuevos hacendados compraban lotes; y las planicies al no tener una configuración espacial con límites que marcaran una radical diferencia entre las tierras de una persona y otra, ellos iban aprovechando tal situación para ampliar sus terrenos. El valle del Patía era un espacio abierto, pero territorializado por gente negra que desde la colonia se habían asentado en él. Ello, posibilitó en segunda instancia, que bajo diferentes estrategias las tierras de estos colonos fueran adquiriendo el carácter legal. En tercera instancia, esto fue posible gracias al poco valor que le otorgaba el negro patiano a la tierra -al ser un espacio abierto, no había necesidad de luchar por esta-, por lo tanto, el prestigio y la autoridad se basaban en el número de reses que la persona tuviese. Frente a estas formas de perdida de la tenencia de la tierra, nos encontramos el siguiente relato por un habitante local:

A mí tía Anunciación le asignaron un pedazo de tierra, para ella y Meregilda (la hermana). Esto me lo dijo mí tío Benito (...) Y a Anunciación, le había dicho un rico de la Finca La Marquesa, que él le asignaba un pedazo mejor, que ella soltara el alambre y que él le daba un pedazo mejor. Ella al soltar el alambre el señor se cogió el lote y no le dio nada, porque (ella) perdía la posesión que tenía (...) Fue la forma de quitarle la tierra. (Entrevista a Polo³, ganadero, valle del Patía, octubre de 2018).

Ahondando en relación con este tema, una de las explicaciones las encontramos en las palabras del antropólogo Manuel Ussa:

[...] La forma de tenencia de la tierra de los Patianos, la cual les permitía extenderse casi indefinidamente, debido a la imprecisión de los linderos y debido al escaso valor monetario que se le otorgaba a la tierra, empezaron a comprar lotes y mejoras a los negros, y ante la facilidad de comprar el alambre de púas fueron cercando y desplazando poco a poco a sus antiguos propietarios [...] hasta configurar lo que hoy se constituyen grandes haciendas ganaderas (Ussa, 1987: 44-45).

Lo anterior nos lleva a pensar en la necesidad de un antes y después. Un antes caracterizado por un dominio económico-político y de apropiación simbólica-cultural (Haesbaert, 2011), por parte de los patianos. En este antes la cultura, "se desenvolvía al ritmo de un calendario en el que se articulaban los ciclos anuales de la producción ganadera y agrícola con las fiestas religiosas"

Seudónimo usado por el entrevistado. Se usa a fin de resguardar su identidad. 
(Zuluaga 1998, 120). Igualmente, en esta geografía, la cultura se cimentaba en la tradición oral en tanto productora de conciencia colectiva y al mismo tiempo, cumplía "el papel conservador y reproductor de cultura, las leyendas y los mitos, las manifestaciones de lo sagrado, rondan la cotidianeidad y crean un clima donde los hombres son acechados, protegidos y contratantes con los duendes, los santos y el diablo" (Zuluaga, 1998: 120). De tal suerte que, "el diario vivir se veía afectado por encantamientos íntimamente relacionados con la producción" (Zuluaga, 1998: 120). Sin embargo, en el después, con la llegada de colonos blanco-mestizos y la consolidación del latifundio ganadero, se produjo un conjunto de cambios en las formas de usar y generar el espacio. Esto llevó, entre otras cosas, a:

[...] 1) la ruptura de circuitos de desplazamiento por esta geografía, 2) la desestructuración de formas de adquisición de productos para la subsistencia como el mate y/o puro ante la prohibición de los nuevos hacendados para ingresar a los predios que históricamente habían sido utilizados para tales fines y, 3) la afectación de formas solidarias individuales y colectivas que garantizaban el mantenimiento de estrategias para la re-existencia como la posibilidad de adquirir la leche del ganado cimarrón o de aquel que pastaba en los potreros abiertos (Albán, 2015: 218)

Como se puede apreciar en la cita, la primera consecuencia es una transformación del sentido del lugar, como resultado de, restricciones en la movilidad y en las prácticas espaciales rutinarias (Oslender, 2008). En efecto, las restricciones a la movilidad y la desestructuración en las formas de adquisición de productos nuevos para la subsistencia se pueden evidenciar incluso hasta más contemporáneamente, el siguiente relato es esclarecedor en ese sentido:

A la finca donde nosotros vamos llamada Miraflores, el señor nos prohibió entrar a cosechar, él ya no quiere dejar entrar a la gente porque en esa finca hay mucho mate. Él nos prohíbe entrar, porque quiere cortar el puro él mismo (Entrevista a Aidé González, citada en Rosas, 2014: 113).

Los nuevos controles impuestos por hacendados blancos/mestizos en sus grandes propiedades en el valle del Patía, implicaron unas dinámicas de desterritorialización y de reterritorialización. Para el geógrafo brasilero Rogerio Haesbaert, la desterritorialización "es el movimiento por el cual se abandona el territorio" (Haesbaert, 2011: 106) y la reterritorialización, "consiste en el movimiento de construcción del territorio" (Haesbaert, 2011: 106). Ambos implican movimientos, en el primero "los agenciamientos se desterritorializan y en el segundo se reterritorializan como nuevos agenciamientos maquínicos de cuerpos y colectivos de enunciación" (Haesbaert, 201: 106). Los movimientos de desterritorialización y reterritorialización conducen a la creación y destrucción de territorios, es decir, configura unas entradas y salidas. En este contexto, los colonos blancos/mestizos que se asentaron en el valle del Patía, en su proceso de territorialización, moldearon unos agenciamientos colectivos de enunciación y agenciamientos maquínicos de deseo (Haesbaert 2011). El primero, implica un régimen de signos que se elabora mediante componentes discursivos, mientras que el segundo se inscribe dentro de componentes no discursivos o sistemas pragmáticos de acciones y pasiones (Haesbaert, 2011), y "dentro de este movimiento mutuo de agenciamientos, un territorio se constituye" (Haesbaert, 2011: 105). 
Los movimientos de territorialización de los colonos blancos/mestizos en el valle del Patía, fueron agenciados, y en un sentido colonizador y represivo por el deseo. El deseo de: ampliar la parcela, rozar el potrero, acabar con las malas hierbas, hacer una finca 0 , por otra parte, la pretensión de comprar o arrebatar a los habitantes nativos la tierra. El deseo de desterritorializar a los negros. "En esta concepción (...) el deseo crea territorios, ya que comprende una serie de agenciamientos" (Haesbaert, 2011: 100). Son los agenciamientos movilizados por el deseo, los que llevaron a la desterritorialización de la gente negra y las transformaciones en el paisaje. Estos traen consigo una serie de violencias simbólicas en las formas de territorialización, tales como el cambio de nombres de los lugares, la prohibición para acceder a cierto tipo de plantas o peces. Igualmente, la deforestación para ampliar los potreros dedicados exclusivamente al ganado, significaron la perdida no solo de flora y fauna nativa en términos de su biodiversidad, sino también de los usos medicinales asociados a ciertas plantas que complementaban la dieta alimentaria. Lo mencionado hasta aquí, nos permite ver como la expoliación a la tierra de la gente negra, configuró no solo unos desplazamientos físicos en el espacio, sino esencialmente unos movimientos que definieron una serie de imposiciones traducidos en violencias simbólicas.

Los movimientos de territorialización de los colonos blancos/mestizos generaron una serie de desterritorializaciones a los patianos. Este proceso, no debe ser entendido como una salida del territorio, sino más bien como una pérdida gradual de la tierra. Para producir una desterritorialización, se necesitan nuevos deseos, "nuevos encuentros, nuevas funciones, nuevos acuerdos" (Haesbaert, 2011: 109), acompañados de nuevas reterritorializaciones. Sin embargo, aquí lo que queremos enfatizar es que los patianos han sido desterritorializados por los colonos, sin necesidad de un desplazamiento físico amplio, sino más bien, a través de la precarización de su calidad de vida, y la negación de sus expresiones simbólicas-culturales y, por ende, espaciales como consecuencia de la expoliación de sus tierras. Desde esta perspectiva, la expoliación se convierte en un campo de luchas materiales/simbólicas por otorgarle distintos significados, usos y sentidos a un espacio en particular. En concreto, en tanto disputas materiales/simbólicas que adquieren el carácter de conflictos por los significados espaciales, son posibles de entender las des y reterritorializaciones en las planicies del río Patía. Frente a esto, los gráficos $\mathrm{N}^{\circ} 1$ y $\mathrm{N}^{\circ} 2$, ilustran la situación en relación con las des y reterritorializaciones.

Gráfico N¹. Estructura agraria en el municipio de Patía

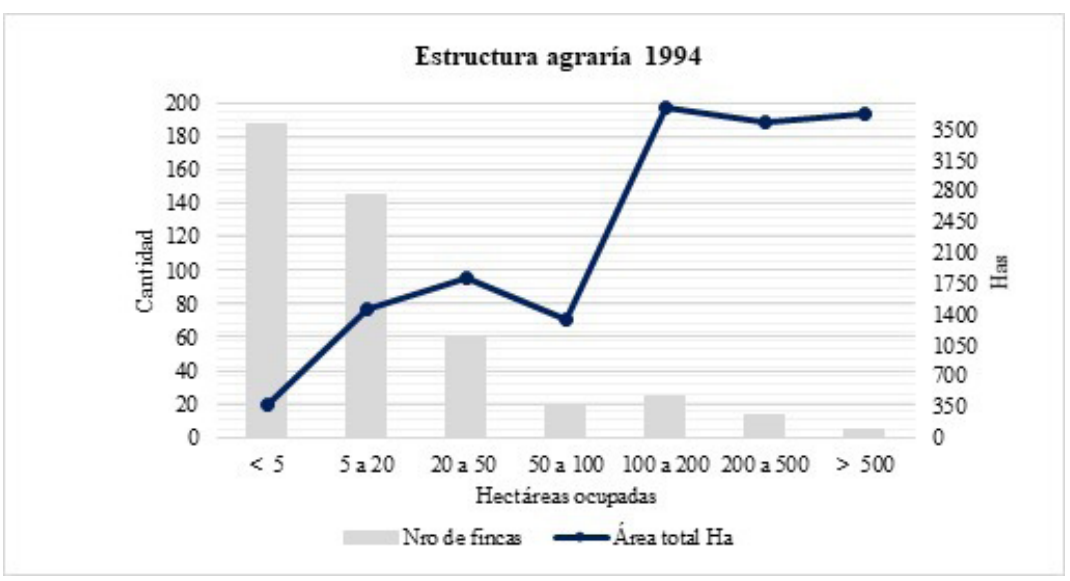

Fuente: elaboración propia con base en Trujillo 1996 
Los datos acerca de los movimientos de desterritorialización y reterritorialización se aprecian en el censo agrario realizado en 1994. . En aquel año, 187 fincas menores de 5 Ha. ocupaban un total de $374 \mathrm{Ha}$. En el rango entre 5 y $20 \mathrm{Ha}$. el número de propietarios o fincas era equivalente a 145 y el total de Ha. fue de 1450. En el intervalo de 20 a $50 \mathrm{Ha}$., el número de fincas o propietarios correspondía a 60 mientras que el área total en $\mathrm{Ha}$. era de 1800. A partir de ahí, ocurre un proceso interesante, entre las 50 y $100 \mathrm{Ha}$. Se encuentran 19 fincas o propietarios y estas representan 1330 Ha. A partir de esta información, se podría pensar que en aquella época los predios hasta con 100 Ha. pertenecían a la gente negra, propiedades heredadas de aquellas familias que eran dueñas de tierras en el valle del Patía y por diversas razones conservaron sus terrenos. Ahora bien, desde el intervalo entre 100 y $200 \mathrm{Ha}$. se puede visualizar en el gráfico cómo el número de propietarios o fincas disminuyó. Sin embargo, el área de terreno aumentó sustancialmente. De este modo, podemos apreciar que el área total representó $3750 \mathrm{Ha}$. distribuidas en 25 predios y/o propietarios. En el rango de 200 y $500 \mathrm{Ha}$. Se encuentran 13 fincas con $3575 \mathrm{Ha}$. Por último, mayores de $500 \mathrm{Ha}$. Se tienen 5 predios y representan un total de $3675 \mathrm{Ha}$. Esto significa que, para el año 1994, cinco personas tenían más tierra que todos los que están en los tres primeros intervalos.

Gráfico N². Estructura agraria en el municipio de Patía

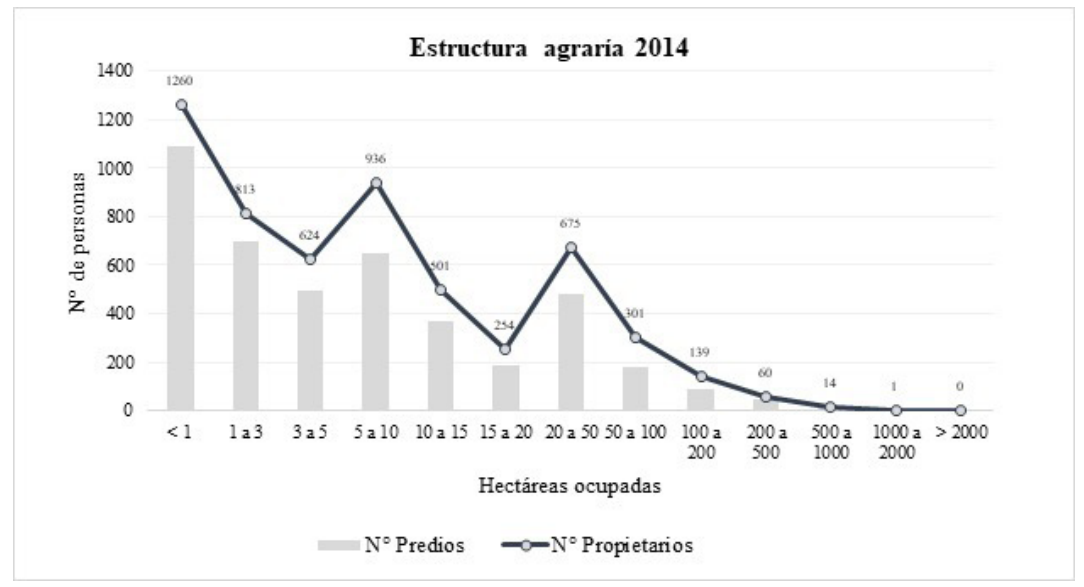

Fuente: elaboración propia con base en IGAC 2014

Veinte años después, tal como se puede apreciar en el grafico $N^{\circ} 2$, la situación no es muy diferente. 1089 predios menores a una Ha. pertenecen a 1260 propietarios. Sin embargo, en el otro extremo, un predio entre las 1000 y $2000 \mathrm{Ha}$. pertenece a una sola persona. Esto es, la desterritorialización y la reterritorialización. Los datos presentados son producto de un contexto histórico y geográfico que comienza desde la década de los años sesenta para los fines de esta investigación. El siguiente relato, aporta elementos complementarios al análisis de los datos anteriores. De acuerdo con un informante local, "varios casos hay en Patía, que siendo propietarios los emborracharon y los llevaron a Popayán y le hicieron firmar. A otros los envenenaron les hicieron firmar y le dieron veneno para matarlos (Entrevista a Gabriel Jiménez ${ }^{4}$, valle del Patía, septiembre. de 2018. Una habitante local comenta lo siguiente frente a ciertos hacendados del Patía: 
esa gente fue de la más mala con los negros. Y muchos de nosotros vivíamos pegados de ellos, los que mandaban y comandaban anteriormente. Pues mire que hasta la fecha eso que es de Mosquera todo eso era de los negros de Patía. Eso que tienen ellos era de mi mamá y mi tía, de herencia que les dejo el abuelo de ellas. Y eso se perdió y se lo cogieron ellos. (Entrevista a Carmenza Castro ${ }^{5}$, ama de casa y agricultora, valle del Patía- 1 de septiembre. De 2018)

Por último, es dable reconocer que lo anterior constituye un ejemplo en el que deseo y movimiento - para usar los términos de Haesbaert inspirado en Deleuze y Guattari- se juntan y producen un territorio cargado no solo de significaciones nuevas, sino también de expoliaciones, pues en unas décadas la gente negra pasó de controlar toda la tierra a ejercer control únicamente sobre los límites de una hacienda con otra. Sin embargo, es pertinente tener en cuenta, que las expoliaciones han creado una serie de improntas en los patianos que les ha permitido no solo resistir, sino como se verá más adelante, re-existir.

\section{Extrahecciones en el valle del Patía: Minería ilegal}

Recientemente se ha acuñado el término extrahección para hacer referencia a conflictos socioambientales provocados por la extracción de recursos naturales, y que, en el proceso de aprovechamiento de estos, se debe apelar a la violación de derechos humanos y de la naturaleza. En este contexto, la extrahección va más allá de la extracción in situ del recurso natural, ya que deja una serie de efectos que se inscriben "en" el espacio a través de la reconfiguración de las prácticas socioespaciales, y a menudo las consecuencias de estas suponen cambios en significados socioculturales que se mantienen más en el espacio/tiempo que los impactos materiales generados. Para que se presente extrahección, en primera instancia tiene que existir la presencia de condiciones de alegalidad, es decir, "prácticas que en su apariencia formal contemplan las exigencias legales, pero sus consecuencias son claramente ilegales" (Gudynas, 2013: 11).

En segunda instancia, otro rostro de las extrahecciones es que muchas son directamente ilegales. Una clara ilustración de ello es la tala de diferentes ecosistemas para la siembra de cultivos de uso ilícito en Colombia y licito, dentro de áreas protegidas. Sin embargo, una de las extrahecciones que reviste mayor atención en la actualidad por su complejidad, es la minería ilegal mecanizada. En concreto, entendemos la minería ilegal mecanizada como una forma de extrahección de un recurso natural, que operando por fuera de los límites legales y en asocio y a través de un conjunto de actores armados ilegales, produce una serie de violencias materiales y simbólicas a los habitantes locales y violaciones a derechos de la naturaleza. Este tipo de extrahección, se caracteriza, además de lo señalado, porque se desarrolla a "cielo abierto, utilizando retros para eliminar la capa vegetal y hurgar las entrañas de la tierra en busca de las vetas auríferas (Restrepo, 2017: 6). Ejemplos de esto, lo constituyen la explotación minera en el norte del Cauca (Restrepo, 2017) o la realizada en El Hoyo-Patía (Melo-Guzmán, 2018) para mencionar dos y sin el ánimo de hacer una búsqueda exhaustiva de extracción ilegales de oro. No obstante, en este apartado, si bien nos concentraremos con mayor hincapié en la extrahección de oro en

Nombre cambiado por el investigador con el fin de resguardar la identidad de la entrevistada. 
el río Sambingo, también dialogaremos con la extrahección de oro en El Hoyo-Patía, a partir del trabajo de Melo-Guzmán (2018), debido a que ambos procesos ocurrieron en el mismo espacio cultural: el valle del Patía.

A finales de 2013, en el periódico de circulación nacional El Espectador, un periodista escribía una nota titulada "Las venas rotas del río Patía" (Bolaños, 2013), un poco más de dos años después, la revista Semana publicó otra que tituló "El primer río que desaparece por completo en Colombia" (Semana, 2016), para alertar sobre la minería ilegal en el río Sambingo. En este intervalo de tiempo, es decir, entre 2013 y 2016 hubo una de las mayores bonanzas mineras en el Patía desde la época colonial. Ahora, eran las retroexcavadoras que habían llegado con el fin de removerlo todo y no dejar un gramo de oro en la tierra. De acuerdo con la etnografía de Melo -Guzmán (2018) sobre la minería en El Hoyo-Patía, las fases en el proceso de extracción de oro con retroexcavadoras eran las siguientes:

(1) con las retroexcavadoras los mineros destruyen la capa vegetal y sacan toneladas de tierra para abrir huecos(...) Abrir un hueco se demoraba un par de días; extraer, separar el oro y recuperar, alrededor de dos semanas por cada hueco. (...) Luego (2), el material extraído por la retroexcavadora es colocado por porciones en el cajón más alto de la máquina clasificadora para separar el oro de los sedimentos. (...) Enseguida (3), se riega el mercurio o azogue, como lo llaman localmente para hacer la aleación. Después se hace la quema, liberando el vapor al aire y dejando solamente el oro concentrado. Por último (4), los residuos son impulsados con la ayuda de grandes cantidades de agua a presión directamente hacia el río junto con los desechos tóxicos, filtrándose también en el suelo. (Melo-Guzmán 2018, 36-37).

Este proceso requiere el uso de altas cantidades de compuestos químicos que luego son desechados en el cauce del río. Durante estas épocas, se acabaron los paseos al río Patía, tan comunes en las épocas de sequía (junio, julio, agosto y septiembre), así como se vio con sospecha el agua de ese drenaje. El líquido del río se tornó de una coloración grisácea, como si tuviese permanentemente cenizas volcánicas. Una de las características de la explotación del oro en El Hoyo y el Sambingo, es que, en ambos lugares, la escasa presencia del Estado y de mecanismos efectivos de control frente a la actividad minera, daba lugar a que se multiplicaran otra serie de conflictos. Una muestra de ello es que:

En un primer momento, los mineros entraban a lavar solamente los planes [o partes planas de los lotes] de las personas que lo permitían, pero conforme encontraban el oro, iban avanzando hacia las orillas de los ríos, arrasando con los cultivos y la arborización que encontraran en el camino. Finalmente, al ver que la pinta de oro iba mejorando conforme se iban desplazando hacia el río, los mineros entraron a lavar en los cauces de los ríos, unas veces con consentimiento y otras sin este (Melo-Guzmán, 2018: 37).

Esto generaba múltiples entramados de conflictividad, en tanto que la búsqueda de oro iba arrasando las fuentes hídricas, las capas vegetales, así como los suelos fértiles, y terminaba afectando a las comunidades negras de la parte baja del valle del Patía que se dedican a la ganadería y agricultura. En los espacios era común debido a la llegada de cientos de barequeros de diferentes lugares del país "la proliferación de los más disímiles negocios como bares, servicio de televisión 
satelital y hasta prostíbulos, en los cuales no pocos gastaban a manos llenas el dinero para regresar al otro día al corte" (Restrepo, 2017: 7).

En este contexto, la minería mecanizada se convirtió en una práctica disruptiva para las comunidades negras de El Hoyo y del río Sambingo, que tuvo una serie de efectos tanto ambientales, como socioculturales en el resto de las poblaciones negras del Patía. Las amenazas a líderes de consejos comunitarios, así como la instauración de unos regímenes de terror se hicieron frecuentes, tal como se puede apreciar para el caso del Sambingo (Mosquera-Vallejo y Paulsen-Espinoza 2020). En el artículo publicado en el periódico El Espectador, en noviembre del 2013, época de auge de la minería ilegal mecanizada en El Hoyo, se presentó una serie de amenazas a líderes comunitarios locales, representantes de consejos comunitarios de comunidades negras. Es más, en el manuscrito de este periódico colombiano se puede apreciar como el nombre de uno de los amenazados es cambiado por cuestiones de seguridad, y una vez se finaliza la visita periodística los líderes comunitarios son nuevamente intimidados. "No se metan con este negocio, porque la minería es una mafia" (Bolaños, 2013: s.p), fue el mensaje enviado a uno de los obligados a salir de su territorio.

Una de las particularidades que se configura en este tipo de minería, es su carácter violatorio de los derechos humanos, de los ecosistemas y a un ambiente sano. En este sentido, es posible analizar a la minería ilegal mecanizada como la desarrollada en el Hoyo y Sambingo, en tanto formas de extrahección de recursos mineros que se despliega a partir de dos epistemologías o sentidos de entender el mundo de manera diferenciada, y al mismo tiempo, como dos ontologías distintas, es decir, dos formas diferentes de existir y relacionarse con el mundo. Lo anterior, se aprecia en la figura $\mathrm{N}^{\circ} 2$.

Figura $\mathrm{N}^{\circ}$ 2. Extrahecciones en el río Sambingo
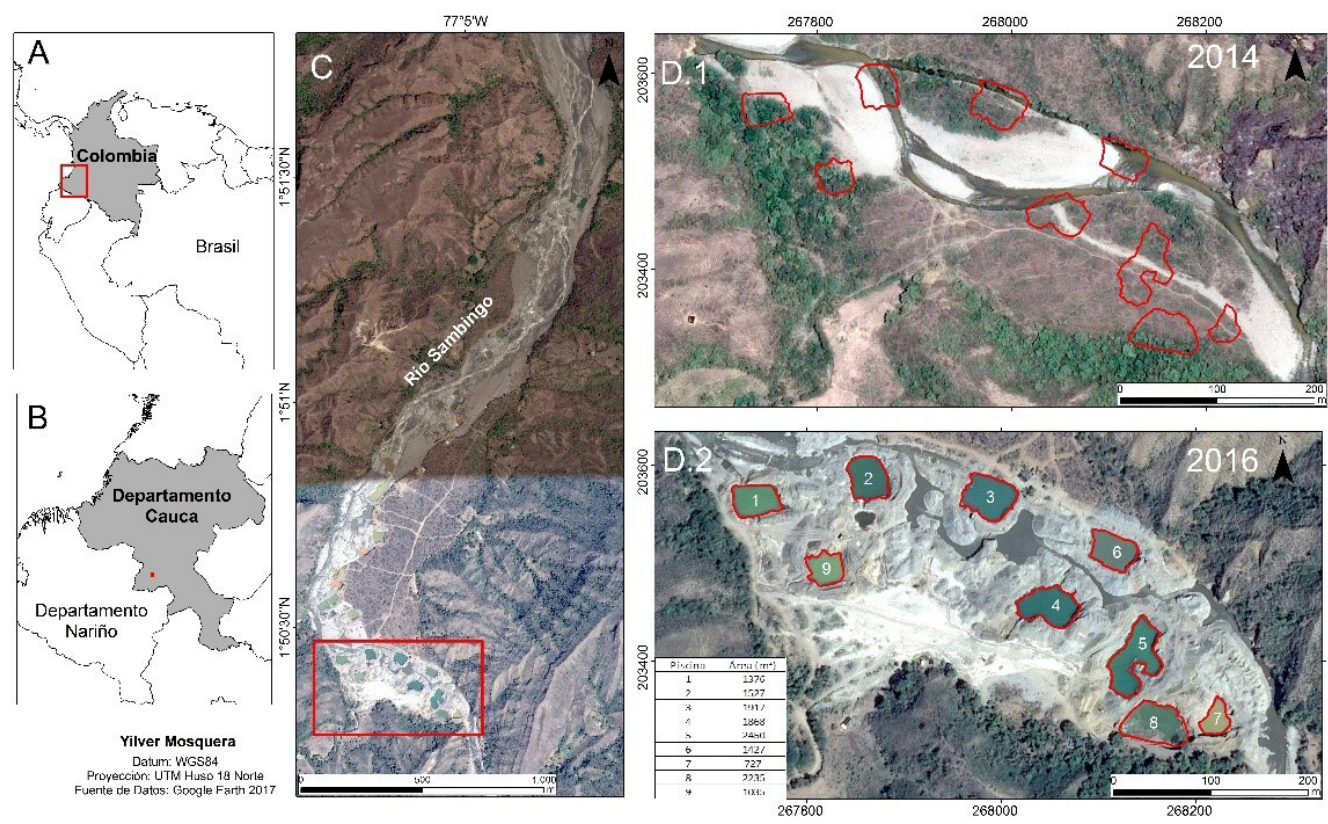

Fuente: Mosquera-Vallejo; Paulsen-Espinoza, 2020. 
En este mapa es posible apreciar el antes y después en estas dos formas de entender y relacionarse con el mundo. En la primera imagen que corresponde al 2014, aún no se desarrollaba en tal magnitud la minería en el Sambingo, mientras que, en El Hoyo ya había minería a gran escala. El caso del río Sambingo tuvo una fuerte exposición ante la opinión pública nacional, debido a la significativa atención que le otorgó la prensa nacional, informando que el río (tributario de la cuenca del río Patía) había desaparecido por completo. Ahora bien, la primera imagen se vincula con unas prácticas y experiencias espaciales de la gente negra históricamente asentada allí, y que expresan, siguiendo a Escobar (2015) mundos u ontologías relacionales, esto es, una "densa red de interrelaciones y materialidad a la que llamamos "relacionalidad" u "ontología relacional" (Escobar 2015 , 29). Estos mundos relacionales agenciados por otros seres y construidos en una telaraña que se "enactúa minuto a minuto, día a día, a través de una infinidad de prácticas que vinculan una multiplicidad de humanos y no-humanos (Escobar, 2015: 29).

En contraposición a esta primera imagen, la segunda es configurada a partir de una ontología dual, basada en la separación de espacio/tiempo, naturaleza/cultura, mente/cuerpo, nosotros/ellos, oriente/ occidente, lo que está llevando a la "erosión sistemática de la base ontológica-territorial de muchos otros grupos sociales, particularmente aquellos donde priman concepciones del mundo no dualistas, es decir, no basadas en las separaciones ya indicadas" (Escobar, 2015: 29). Estas ontologías no son virtualidades o ficciones del mundo. Ellas se hacen paisaje y las podemos representar en imágenes como las presentadas en la figura $N^{\circ} 2$. En esta se visualiza la afectación al recurso suelo, como consecuencia de la remoción de material en el río. Sin embargo, en la extrahección al río Sambingo también se alteró el funcionamiento del ecosistema, debido al uso desproporcionado de insumos químicos, tala de bosque y contaminación del agua. Un informe de la Corporación Autónoma Regional del Cauca-CRC-, autoridad ambiental regional, en una visita realizada el 16 de abril de 2016 sostenía que:

Aun sin recorrer toda el área afectada se puede inferir que la afectación al bosque fue severa, teniendo en cuenta la cantidad de refugios que fueron construidos y toda la leña que fue usada para la preparación de los alimentos, como consecuencia destruyeron los relictos de bosque de galería, situación que conlleva a una pérdida de diversidad biológica y estructural (CRC, 2016: 5).

El retorno de las condiciones naturales a ese ecosistema es bastante complejo, pues este tipo de extrahección genera efectos cuya reversibilidad es mayor a los diez años. Algunas de las piscinas resultantes de la minería ilegal, tienen hasta ocho metros de profundidad y quince de ancho. En definitiva, este tipo de extrahecciones en el valle del Patía es necesario verlas como radicales formas de eliminación de la vida. Sin embargo, en el desarrollo de estos procesos y en el marco de las diferentes experiencias, imbricaciones e improntas por las que están atravesadas las poblaciones negras, emergen ante las extrahecciones procesos de re-existencia. Esta se despliega a través de estrategias, prácticas, tácticas para re-crear la vida (Albán, 2015).

\section{Re-existencias en el valle del Patía: prácticas del "adentro" de la gente negra}

La re-existencia configura una particular forma de existencia y resistencia construida por las poblaciones negras del Patía desde la época colonial. Estos sujetos forjaron parte de sus rela- 
ciones sociales, económicas, territoriales y culturales en condiciones asimétricas frente a la sociedad blanca/colonial/euroandina/esclavista, representada especialmente por ciertas familias de Popayán. Sin embargo, la gente negra a través de sus singulares prácticas, esto es, aquello "que los hombres realmente hacen cuando hablan o cuando actúan" (Castro-Gómez, 2011: 31), se reinventaron en su diferencia. Las prácticas son pensamientos cristalizados articulados en red, es decir, bajo unas conexiones o reglas prestablecidas, y dichas condiciones se registran en el marco de procesos socioculturales e históricos consolidados a partir de relaciones de poder (Castro-Gómez, 2011), en el que dichas reglas o procesos se inscriben y sedimentan a partir de unas condiciones espaciales preestablecidas. Las prácticas es pertinente entenderlas en el contexto histórico en el que emergen, pero también en las condiciones geográficas en las cuales surgen y se desenvuelven. Una práctica parecida, surgida en el mismo periodo histórico, no va a ser idéntica si nace en dos espacios diferentes. La decibilidad, es decir, el conjunto de reglas a partir de las cuales se dice y la factibilidad, esto es, las condiciones de existencia de una práctica resultarán distintas porque probablemente cambia la racionalidad de las prácticas y sus objetivaciones (Castro-Gómez, 2011). Por lo tanto, es necesario historizar y geografizar radicalmente lo que la gente hace cuando habla o actúa en un territorio. A lo que la gente hace en un territorio, le llamaré práctica(s) espacial(es) (Lefebvre, 2013). Esto es, la cristalización de forma(s) de usar, generar y percibir los espacios. Estas prácticas espaciales, las distinguiremos en dos sentidos para el valle del Patía: a) práctica(s) del "adentro" o geosóficas y práctica(s) del "afuera". En este texto, nos interesa reflexionar exclusivamente, y en tanto modalidad de re-existir a las prácticas del "adentro".

\section{Prácticas del "adentro"}

Ellas tienen que ver con los saberes y haceres materiales/simbólicos que se ejercen en el territorio. Las prácticas del "adentro" entonces, suponen el ensamblaje entre aquello que la gente realmente conoce de su territorio, a partir de cómo lo describe, camina y controla. El "adentro" está asociado con aquellas visiones existenciales de la geografía, que J. K Wright (1891-1969), denominaría geosofía. Esto es, "una historia de la Geografía que toma en cuenta no solo el estudio del conocimiento de los académicos sino también de otros sectores sociales" (Zusman, 2013: 53). De este modo, las re-existencias, se anclan en el Patía, en modalidades de construcción del territorio basado en experiencias y conocimientos otros localizados y distribuidos en los "adentros". Estos a su vez, "constituyen los territorios que cada persona percibe, conoce (lo que incluye la posibilidad de hablar de ellos, narrarlos, sentirlos...) y en los que se actúa o se desarrollan las prácticas cotidianas." (Lindon, 2011: 17). En este contexto, las re-existencias se desarrollan en ámbitos desenvueltos en el diario vivir, y se expresa en actividades como: la siembra de productos agrícolas, recolección de frutos silvestres, así como la recolección y uso en la medicina tradicional de plantas frías y calientes. La experiencia de habitar el espacio, y de códigos culturales históricamente creados y espacialmente compartidos por lo patianos, han elaborado estas prácticas del "adentro". Ellas se localizan y distribuyen en diferentes escenarios, que no deben ser explorados, pensados o analizados en tanto espacios fijos o localizaciones cartesianas en el territorio, sino más bien como formas de conocer, ser, hacer y estar en el mundo.

Las prácticas del "adentro" se desarrollan en espacios culturales en el interior del valle, que son objeto de descripciones, representaciones y clasificaciones por parte de los patianos. Así, las vegas, islas, rozas, montañas son territorios con descripciones y significaciones distintas en relación con ellas mismas y con las promovidas desde el pensamiento moderno/colonial. En las 
primeras, por ejemplo se hacen y localizan los secretos, se tornan importantes los ciclos de la luna, adquiere relevancia la mano de la mujer para la siembra de productos agrícolas. Igualmente, estos lugares o escenarios condensan una memoria espacial para sus habitantes, mediante la cual reconocen algunos atributos del lugar, por ejemplo, su carácter pesado, en parte, porque es sólido, lo cual significa que un espacio es pesado, porque es solitario, tiene poco movimiento, por lo tanto, se aleja del mundo de lo humano. Lo anterior sugiere modos de comprender y hacer territorio que responden a lógicas de organización del espacio, distintos a los establecidos por la modernidad euroandina y sus representaciones del espacio (Lefebvre, 2013).

Desde esta perspectiva implica reconocer que los patianos presentan prácticas en su vida cotidiana mediadas por vínculos simbólico/materiales que crean re-existencias. A manera ejemplo, frente a los procesos de expoliación, y como resultado de vivir entre los límites de una propiedad con otra, una táctica común entre muchos patianos que tienen pequeños predios ganaderos, y que colindan con las grandes haciendas ganaderas, consiste en hacer pasos en las cercas de alambres de púas, para que sus vacas pasten, entre las cinco de la tarde hasta las cinco de la mañana del día siguiente en los potreros de los grandes hacendados. Ahí, sutilmente, tenemos una re-existencia inscrita en la vida cotidiana, y que se destila en el espacio. Frente a las extrahecciones, actividades que no respetan derechos humanos y de la naturaleza, como la minería ilegal, la estrategia de algunos patianos ante la desigual correlación de fuerzas con los mineros fue optar por el silencio. En estos contextos, y en ocasiones, el silencio es garantía para afrontar la adversidad, en condiciones de dignidad. Sin embargo, no sobra destacar que, se hicieron cartas de rechazo a la minería ilegal, incluso ante el entonces presidente de Colombia Juan Manuel Santos, así como diferentes visitas por parte de la autoridad ambiental local (Mosquera-Vallejo; Paulsen-Espinoza 2020). En definitiva, las re-existencias se articulan en sentidos interrelacionados sentidos. Uno representa re-elaboración de la resistencia y existencia, en nexo con la construcción de subjetividades, territorialidades y saberes otros. Esto es, formas de hacer y decir que adquieren diferente significatividad espacial en relación con el "adentro" y con las epistemologías surgidas desde la ontología del mundo moderno/colonial.

\section{Comentarios finales}

Los procesos analizados en el valle del Patía dan cuenta de sus transformaciones territoriales, ocurridas a partir de la expoliación iniciada en la década de los años sesenta, así como la extrahección desencadenada aproximadamente desde el 2014 con el desarrollo de la minería ilegal mecanizada. Junto con esto, nos propusimos estudiar las re-existencias que, bajo un carácter escurridizo, operan en los escenarios de interacción social cotidiana.

Las expoliaciones dieron cuenta de un proceso gradual, que ha consistido en la perdida de tierra por parte de la gente negra ante colonos blancos/mestizos. Sin embargo, esto debe ser leído con matices. En el valle del Patía, si bien es cierto que gran parte de la tierra se encuentra en manos de hacendados, otra parte quedó en manos de gente negra que históricamente ha tenido tierra. En este aspecto es importante subrayar que los procesos de expoliación en el valle que se articulan con desterritorializaciones de gente negra y reterritorializaciones por parte de colonos blancos/mestizos, es que la perdida de la tierra no significó en los imaginarios espaciales de los habitantes del Patía, que este había dejado de ser un territorio de gente negra. De hecho, este es 
reconocido como uno de esos espacios de la negridad en Colombia, debido a la presencia histórica de comunidades negras en él. Igualmente, desde comienzos de la presente década alguna tierra comenzó a ser "recuperada", a través de la compra por parte del Estado a los hacendados para los consejos comunitarios de comunidades negras. Ello no ha estado exento de dificultades, pues la expoliación ha configurado un tipo de subjetividades negras articuladas con el deseo. Este obra como un péndulo, no es únicamente el colono quien tiene deseos de controlar toda la tierra, la gente negra también. Sin embargo, como toda sociedad, llena de contrastes y más desencuentros que encuentros, los controles que quieren ejercer algunos negros son básicamente de la misma forma en que hasta ahora lo ha hecho el mundo blanco/mestizo. Esto es, desean ser los nuevos hacendatarios. Sin embargo, este es un proceso largo, en donde las apuestas académicas, políticas, culturales, entre otras, deben proponer dinámicas de descolonización posibles de lograr a través de un trabajo político que interiorice en la gente la necesidad de recuperar la tierra para trabajarla comunitariamente, y no bajo las mismas lógicas del capital.

Frente a la extrahección resultado de la minería ilegal mecanizada, vale la pena insistir en la necesidad de seguir articulando procesos de defensa del territorio desde los consejos comunitarios de comunidades negras. De hecho, frente a este tipo de dinámicas de explotación, el esencialismo estratégico y la movilización activa pueden representar importantes herramientas -que no han sido exploradas lo suficientes, pues estos consejos comunitarios, así como la gente negra que hace parte de ellos, no están exentos de múltiples contradicciones-, para la defensa de los derechos humanos y de la naturaleza o, dicho de otra manera, los derechos socionaturales. De hecho, y como diría Fanon "todo el mundo parece conocer estas cosas; pero, en verdad, nadie en lo absoluto las tiene en cuenta" (Fanon, 1966: 170). Las consecuencias ambientales de las extrahecciones han sido inmediatas. Las transformaciones del paisaje en los ámbitos que se desarrolló la minería mecanizada han sido brutales. Así mismo, el derecho a un ambiente sano, entre otros, ha sido alterado, pues la contaminación del río cambió ciclos naturales y dinámicas socioculturales, especialmente en las gentes negras que se asientan cerca de los ríos que fueron objeto de la minería ilegal, y a pesar de todo esto, los liderazgos negros que toman partido en defensa de la vida son escasos. El silencio, ante enemigos poderosos, es también una forma de re-existir.

Los procesos culturales, territoriales, construcción de subjetividades otras caracterizado como re-existencias, son parte de la vida cotidiana de los patianos, y a su vez tratan de ser eliminados, cooptados, saturados, subsumidos desde ciertas lógicas económicas-políticas agenciadas por las epistemologías y ontologías del mundo moderno/colonial. En estas últimas, "nuestro universo lógico se estanca en su espacio riguroso, en esta masa exuberante que se pudre sin dejar pasar la luz, donde la vida brota incesantemente sobre lo muerto, donde el fango exhala la insipidez de la muerte" (Dardel, 1990: 50). Contrario al espacio riguroso, las re-existencias incorporan existencias que no se reducen a realidades objetivas. Ellas son flujos de olores, colores, sabores, que se entremezclan y construyen territorialidades, produce subjetividades que se localizan y distribuyen en diferentes niveles de sentido. Es precisamente esto que ha permitido a la gente negra, mantenerse ante los procesos de expoliación y extrahección descritos, pues si bien es cierto que existe una gran concentración en la estructura de la tenencia de la tierra, también es posible concluir junto con el geógrafo Carlos Walter Porto-Gonçalves que re-existir es:

más que "resistencia", que significa reaccionar ante una acción anterior y así, es siempre un acto reflejo, tenemos re-existencia. Es decir, una forma de existir, una determinada ma- 
triz de racionalidad que actúa en las circunstancias, inclusive re-actúa, a partir de un topoi, en fin: de un lugar propio, tanto geográfico como epistémico. En verdad, actúa entre dos lógicas» (Porto-Gonçalves, 2006: 165).

\section{Referencias bibliográficas}

ALBÁN, A. Patianos allá y acá; Migraciones y Adaptaciones Culturales 1950-1997. Popayán: Fundación pintáp Mawá, 1999.

ALBÁN, A. Sabor, poder y saber. Comida y tiempo en los valles afroandinos del Patía y Chota-Mira. Popayán: Universidad del Cauca, 2015.

BOLAÑOS, E. Las venas rotas del río Patía. El Espectador, Bogotá, 4 nov. 2013. Recuperado de www.elespectador.com

CASTRO-GÓMEZ, S. Historia de la gubernamentalidad. Razón de Estado, liberalismo y neoliberalismo en Michel Foucault. Bogotá: Siglo del hombre editores/instituto pensar, 2011.

C.R.C. 2016. Informe Técnico en atención a acciones de Protección y Vigilancia de los Recursos Naturales y el Ambiente, como acción de oficio al río Sambingo, corregimiento de Cajamarca, municipio de Mercaderes, por extracción ilegal de minerales. Inédito, 2016, p.1-10.

DARDEL, E. L'Homme et la Terre. Nature de la réalité géographique. Éditions du CTHS, 1990.

ESCOBAR, A. Territorios de diferencia: la ontología política de los «derechos al territorio. Cuadernos de antropologia social, 2015, № 21, p. 25-38.

ESCOBAR, A. El final del salvaje: naturaleza, cultura y política en la antropología contemporánea. Bogotá: ICAN, 1999.

IGAC. Estadísticas de distribución de la propiedad rural en el municipio de Patía. Inédito, 2014.

FANON, F. Antillanos y africanos. Revista Casa de las Américas, 1966, Vol. 6, Nº 36-37, p. 169-174.

GROSFOGUEL, R. El concepto de «racismo» en Michel Foucault y Frantz Fanon: ¿teorizar desde la zona del ser o desde la zona del no-ser? Tabula Rasa, 2012, № 16, p. 79-102.

GROSFOGUEL, R. Del «extractivismo económico» al «extractivismo epistémico» y al «extractivismo ontológico»: una forma destructiva de conocer, ser y estar en el mundo. Tabula Rasa, 2016, $\mathrm{N}^{\circ}$ 24. Disponible en internet: https://doi.org/10.25058/20112742.60

GUDYNAS, E. Extracciones, extractivismos y extrahecciones. Un marco conceptual sobre la apropiación de recursos naturales. Centro Latinoamericano de Ecología Social, Observatorio del desarrollo, 2013, No 18, p. 1-18. 
HAESBAERT, R. El miro de la desterritorialización del "fin de los territorios" a la multiterritorialidad. México: Siglo XXI Editora Iberoamericana, 2011.

HIDALGO, R.; ALVARADO, V. \& SANTANA, D. Los expulsados de la metrópoli: expolio y esquilmo en la locación de la vivienda social en la ciudad neoliberal. Una perspectiva de Santiago y Valparaíso. Estudios socio-territoriales. Revista de geografía, 2016, № 20, p. 41-55.

KOWARICK, L. Expoliación Urbana, Luchas Sociales y Ciudadanía: Retazos De Nuestra Historia Reciente. Estudios Sociológicos, 1996, vol. 14, № 42, p. 729-743

LEAL, C. \& RESTREPO, E. Unos bosques sembrados de aserríos. Historia de la extracción maderera en el Pacífico colombiano. Medellín: Colciencias - ICANH, Colección Clío, Convenio Universidad de Antioquia - Universidad Nacional de Colombia, Sede Medellín, Facultad de Ciencias Humanas y Económicas, 2003.

LEFEBVRE, E. La producción social del espacio. Madrid: Capitán Swing, 2013.

LEFF, E. La Esperanza de un Futuro Sustentable: Utopía de la Educación Ambiental. Conferencia presentada en el VI Congreso Iberoamericano de Educación Ambiental, San Clemente de Tuyú, Argentina, 17 de septiembre de 2009. Disponible en internet: http://www.sustentabilidades.usach. $\mathrm{cl} /$ sites/sustentable/files/paginas/05.pdf

LINDÓN, A. La educación geográfica: Del transitar los espacios de proximidad a la socialización espacial. Anekumene, 2011, Vol. 1, No 1, p. 14-27.

MALDONADO-TORRES, N. El arte como territorio de re-existencia: una aproximación decolonial. Iberoamérica Social: revista-red de estudios sociales, 2017, Vol. VIII, p. 26-28.

MELO-GUZMÁN, J. Lavando el oro del Patía: conflicto, despojo y resistencia en la comunidad negra de El Hoyo (Cauca, Colombia). Tesis de Maestría, Programa de Antropología. Brasilia: Universidad de Brasilia, 2018.

MINA, M. Esclavitud y libertad en el valle del Río Cauca. Bogotá: Publicaciones de La Rosca, 1975.

MOSQUERA-VALLEJO, Y. Escala geográfica: visibilidades e invisibilidades en procesos socioculturales afrodescendientes. Revista CS, 2020, N³0, p. 251-276. http://dx.doi.org/10.18046/recs. i30.3330.

MOSQUERA-VALLEJO, Y; ESPINOZA-PAULSEN, A. Geografía del extractivismo: conflicto socioambiental en el río Sambingo. Reflexiones desde la ética ambiental. Estudios Socioterritoriales. Revista de geografía. 2020, № 27, p 1-19. Doi: https://doi.org/10.37838/unicen/est.27-043

OFFEN, K. O mapeas o te mapean: Mapeo indígena y negro en América Latina. Tabula Rasa, 2009, $N^{\circ} 10$, p. 163-190. Disponible en internet: http://www.revistatabularasa.org/numero10/ 
OJEDA, D.; PETZL, J.; QUIROGA, C.; RODRÍGUEZ, A.C. \& ROJAS, J. G. Paisajes del despojo cotidiano: acaparamiento de tierra y agua en Montes de María, Colombia. Revista de Estudios Sociales, 2015, $N^{\circ} 54$, p. 107-119.

OSLENDER, U. Espacio, lugar y movimientos sociales: hacia una "espacialidad de resistencia". Scripta Nova. Revista electrónica de geografía y ciencias sociales, 2002, Vol. VI, No 115. Disponible en internet: http://www.ub.edu/geocrit/sn/sn-115.htm

OSLENDER, U. "Geografías del terror": un marco de análisis para el estudio del terror. Scripta Nova. Revista Electronica de Geografía y Ciencias Sociales, 2008, Vol. XII, Nº 270.

PALACIO, G. Fiebre de tierra caliente. Una historia ambiental de Colombia 1850-1930. Colección En Clave de Sur. 1a ed. Bogotá D.C: ILSA, 2006.

PORTO-GONÇALVES, C. Da geografia às geo-grafias: um mundo em busca de novas territorialidades. En: CLACSO, Consejo Latinoamericano de Ciencias Sociales. La Guerra Infinita: Hegemonía y terror mundial. Buenos Aires: CLACSO, 2001, p. 217-256.

PORTO-GONÇALVES, C. A reinvenção dos Territórios: a experiência latino-americana e caribenha. En: CECEÑA, A. Los desafíos de las emancipaciones en un contexto militarizado. Buenos Aires: CLACSO, 2006, p. 151-197.

REAL ACADEMIA ESPAÑOLA: Diccionario de la lengua española, 23.a ed., [versión 23.3 en línea]. https://dle.rae.es s.f.

RESTREPO, E. Etnización de la negridad: la invención de las "comunidades negras" como grupo étnico. Popayán: Editorial Universidad del Cauca, 2013.

RESTREPO, E. Afrodescendientes y minería: tradicionalidades, conflictos y luchas en el Norte del Cauca, Colombia. Vibrant: Virtual Brazilian Anthropology, 2017, Vol. 14, № 2, p. 225-239.

ROSAS, L. Vivimos del mate: Voces y testimonios de mujeres afropatianas. Popayán: Universidad del Cauca, 2014.

SEMANA. El primer río en Colombia que desaparece por completo, 2016 [18 -11-2018]. Disponible en internet: https://www.semana.com/nacion/articulo/fenomeno-de-el-nino-se-seca-el-primerrio-en-colombia/458485

TRUJILLO, S. Patía. Memoria y desafío. Aproximación a la concepción de territorio. Tesis de grado. Programa de Antropología. Popayán. Universidad del Cauca, 1996.

USSA, M. El descarne: tierra, ganado y cultura del negro patiano. Tesis de Grado. Programa de Antropología. Popayán: Universidad del Cauca, 1987. 
VELANDIA, P. \& RESTREPO, E. Estudios afrocolombianos: balance de un campo heterogéneo. Tabula Rasa, 2017, № 27, p. 161-197.

WADE, P. Los guardianes del poder: biodiversidad y multiculturalidad en Colombia. En: RESTREPO, E. \& ROJAS, A: Conflicto e (in)visibilidad: Retos en los estudios de la gente negra en Colombia. Popayán: Editorial Universidad del Cauca, 2004, p. 247-268.

ZULUAGA, F. Los hombres históricos del Patía o los héroes del tiempo encantado. En: INSTITUTO COLOMBIANO DE ANTROPOLOGÍA E HISTORIA. Geografía Humana de Colombia: Los Afrocolombianos. (tomo VI), Bogotá: Instituto Colombiano de Antropología e Historia, 1998, p. 13-59.

ZUSMAN, P. La geografía histórica, la imaginación y los imaginarios geográficos. Revista de Geografía Norte Grande, 2013, № 54, p. 51-66. 
